\title{
Lenhos fósseis da Formação Missão Velha, Bacia do Araripe: significado geológico com base em feições tafonômicas e sedimentológicas
}

Missão Velha Formation fossil woods, Araripe Basin, Brazil:

Geologic meaning based on taphonomy and sedimentology features

\author{
Aerson Moreira Barreto Junior ${ }^{1}$ (D), Gelson Luís Fambrini ${ }^{2}$ (D), \\ Virginio Henrique de Miranda Lopes Neumann² (1), \\ Wellington Ferreira da Silva Filho ${ }^{3}$ (D), Edison Vicente Oliveira ${ }^{2}$ (b) \\ ${ }^{1}$ Universidade Federal de Pernambuco - UFPE, Programa de Pós-Graduação em Geociências, \\ Av. da Arquitetura, s/n, CEP: 50740-550, Cidade Universitária, Recife, PE, BR (ambarretojunior@gmail.com) \\ ${ }^{2}$ Universidade Federal de Pernambuco - UFPE, Recife, PE, BR \\ (gelson.fambrini@ufpe.br; neumann@ufpe.br; vicenteedi@gmail.com) \\ 3Universidade Federal do Ceará - UFC, Fortaleza, CE, BR (welfer@ufc.br)
}

Recebido em 4 de setembro de 2020; aceito em 4 de outubro de 2021.

\begin{abstract}
Resumo
O presente trabalho versa sobre novas ocorrências de lenhos fósseis nos municípios de Missão Velha, Abaiara e Milagres, bem como investiga suas características tafonômicas e sedimentológicas. Os fósseis observados podem ser categorizados em três estágios sequenciais de exposição: lenhos in situ, presentes em seu depósito original; lenhos exumados, resultantes da denudação da rocha hospedeira; e lenhos ex situ, deslocados por transporte sedimentar ou por ação antrópica. Os lenhos in situ podem ser primários, correspondendo a uma assembleia alóctone, ou secundários, lenhos silicificados retrabalhados que se comportam como seixos nos arenitos da unidade. Lenhos de grande porte foram pouco transportados e estão próximos aos sítios de fossilização. Fragmentos de lenhos muito degradados confundem-se com cascalho e um estudo petrográfico como este pode auxiliar na sua identificação.
\end{abstract}

Palavras-chave: Bacia do Araripe; Neojurássico; Lenhos silicificados.

\section{Abstract}

The present study discussed on new fossil wood occurrences in the counties of Missão Velha, Abaiara, and Milagres, and investigates its taphonomy and sedimentology. The observed fossils are exposed in three sequential stages: in situ woods, present in their original deposit; exhumed woods, resulting from host rock denudation, and ex situ woods, displaced by sedimentary transport or by human action. In situ woods are considered as primary occurrences, corresponding to an allochtonous assembly, or secondary occurrences, as silicified reworked trunks behaving as pebbles in Missão Velha Formation sandstones. Larger woods were transported only by short distances from the fossilization sites. Too degraded wood fragments are usually taken as rock pebbles and lack of a petrographic study, which could aid a proper identification of these samples.

Keywords: Araripe Basin; Late Jurassic; Silicified woods. 


\section{INTRODUÇÃO}

Referindo-se à Bacia do Araripe, o contexto paleontológico é quase automaticamente vinculado aos peixes e pterossauros fósseis do Grupo Santana (sensu Neumann e Cabrera, 1999), e raramente aos lenhos silicificados que ocorrem nos depósitos jurássicos. A presença dos lenhos fósseis na Formação Missão Velha foi escassamente relatada na literatura durante o século XX, vindo a tomar papel de algum destaque apenas com a concepção do Geoparque Araripe, por meio da qual foi reconhecido, em 2006, pela Organização das Nações Unidas para Ciência e Cultura (UNESCO) e originou, dentre os nove geossítios existentes, o Geossítio Floresta Petrificada do Cariri, notório pela abundância dos lenhos silicificados e por ser seção-tipo da Formação Missão Velha (Ponte e Appi, 1990; Freitas et al., 2008; Silveira et al., 2012; Silva Filho et al., 2015; Fambrini et al., 2017).

A primeira menção dos lenhos silicificados da Formação Missão Velha remonta ao tempo da Comissão Científica do Império, que explorou, entre 1859 e 1861, os recursos geológicos, botânicos, faunísticos e etnográficos da Província do Ceará (Alemão e Alemão, 1862). O cronista daquela viagem e poeta notável da literatura brasileira, Antônio Gonçalves Dias, foi o primeiro a reportar a existência de certo afloramento na localidade chamada de São Pedro, situada entre as vilas do Crato e Milagres, em que se encontrava "madeira petrificada" juntamente aos arenitos (Sousa-Brasil, 1863; Hartt e Agassiz, 1870).

Branner (1890), ao fazer um panorama da geologia da Bacia Sergipe-Alagoas, menciona a exposição em abundância de lenhos silicificados transportados juntos aos arenitos dessa bacia. Nesse mesmo trabalho, o autor proporia que as rochas da região do Crato e Jardim (Ceará), Tacaratu (Pernambuco) e também aquelas da Bacia Sergipe-Alagoas que pertenceriam a uma só bacia interligada em tempos pretéritos. Apenas quase um século depois, Beurlen (1963) mencionaria os lenhos silicificados da Bacia do Araripe e Braunn (1966) correlacionaria esses fósseis aos lenhos presentes na Formação Sergi da Bacia do Recôncavo-Tucano-Jatobá.

A gênese comum dessas bacias mencionadas e de outras bacias interiores do Nordeste está relacionada ao estágio inicial do rifteamento do Gondwana durante o Jurássico. Essa fase é marcada pela formação de uma longa, estreita e rasa calha de estiramento, com extensão desde o sul da Bahia e limitada ao norte pelo Lineamento da Paraíba. Essa paleobacia foi designada por Viana et al. (1971) como Depressão AfroBrasileira. O início da sedimentação nessa bacia se deu no Neotriássico (Silva et al., 2012), tendo seu desenvolvimento durante o Jurássico e prosseguindo durante o clímax de rifte no Cretáceo. Nessa fase a bacia compõe-se exclusivamente de depósitos continentais, com sistemas fluviais, lacustres e eólicos (Ghignone, 1979). A área de abrangência desse depósito estendia-se do Brasil, na porção meridional da Região Nordeste, à África, nas porções equatoriais de Guiné, Gabão,
Congo e Angola, compreendendo um depósito original com área superior a $300.000 \mathrm{~km}^{2}$ (Kuchle et al., 2011).

A deposição sedimentar sobre essa vasta extensão territorial corresponde a uma sequência de folhelhos e siltitos vermelhos recobertos por arenitos médios a grossos, representados, no Brasil, pelas formações Aliança e Sergi, na Bacia do Recôncavo-Tucano-Jatobá, e seus equivalentes: formações Bananeiras e Serraria (Bacia Sergipe-Alagoas), Brejo Santo e Missão Velha (Bacia do Araripe), e Agoula, M'Vonne e N'Dombo (Bacia do Gabão) (Kuchle et al., 2011).

Os depósitos da Depressão Afro-Brasileira, de idade neojurássica, correspondem às camadas fossilíferas mais antigas da sequência continental mesozoica. Tais camadas contêm os ostracodes lacustrinos Bisulcocypris e Metacypris, espécimes que apresentam dimensões reduzidas e são predominantes. Lado a lado com B. pricei, o principal fóssil-guia, é encontrado Darwinula cf. D. oblonga (Roemer), razoavelmente frequente e de dimensões normais; conchostráceos e restos de peixes são também encontrados e, na porção superior da sequência, onde a presença de microfósseis é rara, são encontrados lenhos silicificados de coníferas em algumas localidades, distribuídos dentro de uma espessa camada arenosa (Viana, 1980), representada na Bacia do Araripe pela Formação Missão Velha.

Embora a presença de lenhos silicificados nos arenitos da Formação Missão Velha tenha sido relatada desde o século XIX, são escassos os trabalhos que investigam sua distribuição estratigráfica e seu significado paleoambiental (e.g. Freitas et al., 2008; Pires e Guerra-Sommer, 2009, 2011). O presente trabalho discute, por meio de novas evidências de campo, as características tafonômicas e sedimentológicas dos lenhos silicificados da Formação Missão Velha, baseando-se na análise de sua distribuição estratigráfica e de suas formas de exposição.

\section{AFLORAMENTOS}

A área de exposição dos lenhos silicificados compreende os municípios da região do Vale do Cariri (Figura 1), extremo sudeste do estado do Ceará. Quatro novos sítios de exposição de lenhos silicificados nos municípios de Missão Velha, Milagres e Abaiara são reportados neste trabalho, nomeados e descritos com relação à sua localização, com uma breve descrição dos afloramentos e de suas condições fisiográficas, a serem apresentados na próxima seção. Todas as coordenadas UTM apresentadas correspondem à zona 24S (DATUM Sirgas 2000).

\section{Cachoeira do Macêdo}

As exposições da localidade Cachoeira do Macedo (485822/9198044; 485697/9197828) situam-se $1 \mathrm{~km}$ ao 


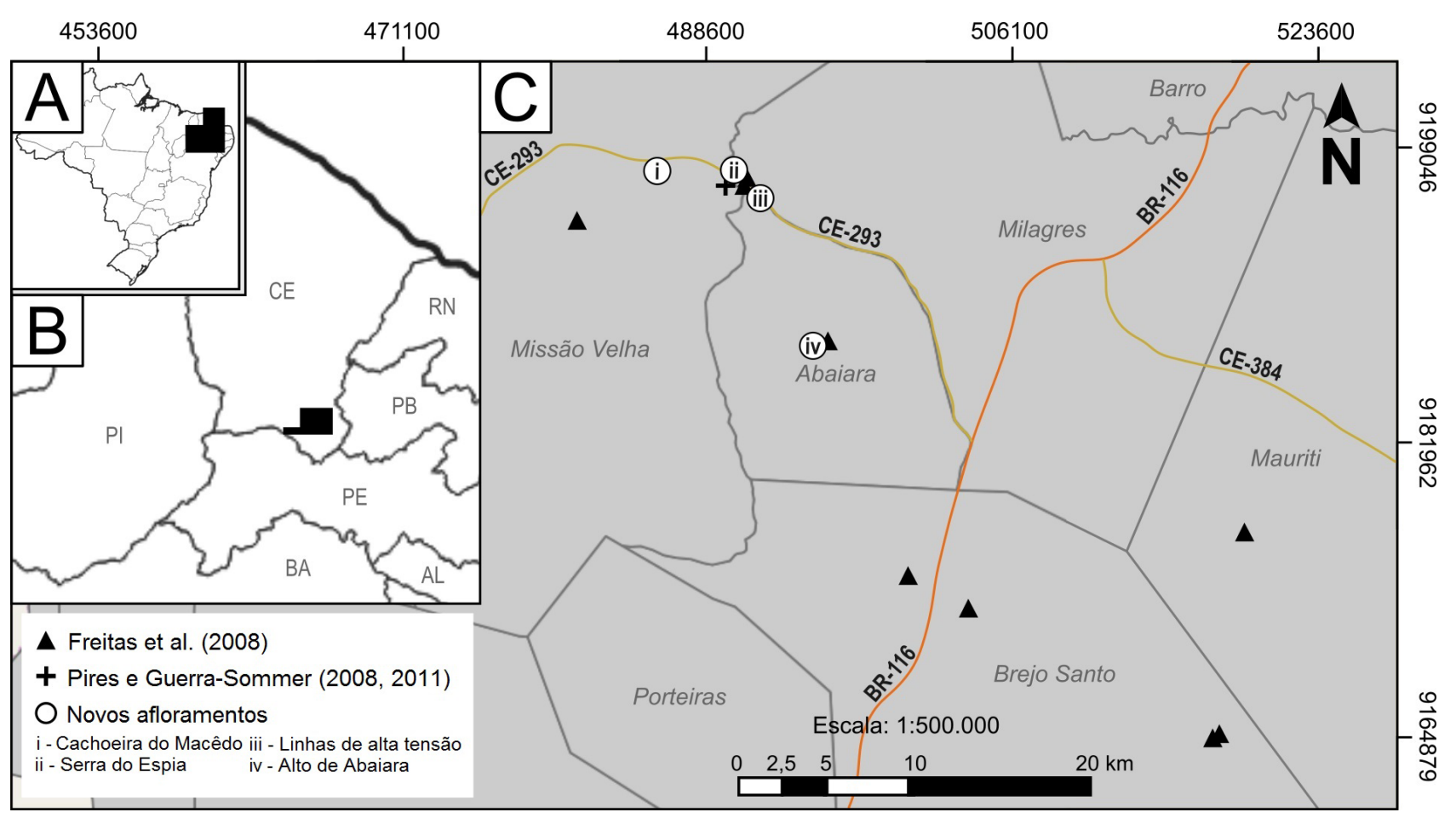

Figura 1. Mapa de localização. (A) Mapa do Brasil; (B) Mapa regional da porção sul do estado do Ceará; (C) região do Vale do Cariri, com as localizações anteriormente publicadas e os novos afloramentos de lenhos silicificados da Formação Missão Velha.

leste de Missão Velha, acessadas pela saída leste desse município por via carroçável a partir da CE-293 (Figura 1C). Nessa localidade afloram sucessões de arenitos finos a médios intercalados com pelitos avermelhados, ocorrendo no topo da sequência um pacote arenítico grosso a conglomerático, com estratificações cruzadas e de aspecto laterítico. É comum haver no afloramento matacões dos níveis areníticos e grande abundância de cascalhos silicosos e quartzosos, não observados nos estratos conglomeráticos.

\section{Serra do Espia}

Os afloramentos da Serra do Espia (490463/9197263; 490500/9197325; 490566/9197278) estão situados a menos de $1 \mathrm{~km}$ ao oeste do Geossítio Floresta Petrificada do Cariri, acessado a partir da CE-293, $5 \mathrm{~km}$ ao leste de Missão Velha (Figura 1C). Por tratar-se de um pasto sobre uma colina, os afloramentos rochosos são escassos nessa localidade, em forma de pequenas escarpas ou em ravinamentos, embora blocos de arenitos sejam abundantes junto ao regolito. A sucessão sedimentar nessa localidade se expressa de forma distinta em suas seções basal e superior. Na seção inferior afloram arenitos, médios a finos, estratificados e raramente apresentando porções conglomeráticas, intercalados com níveis milimétricos de pelitos arroxeados e esbranquiçados. As porções conglomeráticas, quando ocorrem, trazem fragmentos líticos dos estratos pelíticos e raramente seixos quartzosos são observados. São abundantes cascalhos no substrato. Na seção superior ocorrem arenitos grossos a muito grossos, conglomeráticos, bem estratificados, impregnados em ferro e com presença de nódulos metálicos.

\section{Linhas de alta-tensão}

O afloramento das linhas de alta-tensão (491629/9195760) está situado no município de Abaiara, sendo seu acesso possível após percorrer $0,5 \mathrm{~km}$ em uma estrada carroçável que parte da CE-293, 8,5 km ao leste de Missão Velha (Figura 1C). Essa localidade apresenta aberturas artificiais de vias, expondo rochas que estavam sob vegetação e solo. Ocorrem arenitos feldspáticos, médios e médios a grossos, com níveis conglomeráticos, com a presença de um nível de arenitos médios de aspecto laterítico no interior da sequência.

\section{Alto de Abaiara}

O afloramento no Alto de Abaiara (494981/9187441) é acessado percorrendo $500 \mathrm{~m}$ em uma via que parte da estrada para Abaiara, a $8 \mathrm{~km}$ do seu início na CE-293 (Figura 1C), a menos de $1 \mathrm{~km}$ das exposições da Formação Missão Velha no Morro do Cruzeiro (Fambrini et al., 2011, 2017). 
Essa localidade apresenta um patamar escarpado em que afloram sucessões de arenitos médios a grossos, predominantemente arroxeados, com variegação de cores esbranquiçadas e amareladas, e lentes delgadas de arenitos grossos conglomeráticos a conglomerados.

\section{REVISÃo FACIOLÓGICA}

O estudo faciológico e estratigráfico da Formação Missão Velha é descrito e tem suas principais fácies reconhecidas por Fambrini et al. $(2009,2011,2017)$, expressas na Tabela 1. A fácies identificada por esses autores como portadora dos lenhos fósseis, denominada $A c g$ (fácies de arenitos conglomeráticos), é formada por arenitos muito grossos a conglomeráticos de grânulos até seixos, quartzosos, localmente conglomerados de seixos, de coloração amarelo esbranquiçada, formando ciclos granodecrescentes, denominados anteriormente como Fácies B por Cavalcanti e Viana (1992). A geometria dos corpos areníticos é predominantemente lenticular, em que os pacotes arenosos ocorrem amalgamados. Nessa fácies são observadas estratificações cruzadas acanaladas de pequeno e médio porte $(0,2-1 \mathrm{~m})$, estruturas de corte e preenchimento e com concentração de clastos bem arredondados a subangulosos nos estratos frontais das estratificações. Ocorrem níveis lenticulares de seixos na base das camadas ou dos estratos cruzados, ou, em alguns casos, marcando base erosiva. Essa fácies é interpretada pelos autores como depósitos de dunas subaquáticas de regime de fluxo inferior em canais fluviais entrelaçados.

\section{FORMAS DE EXPOSIÇÃO}

Os lenhos silicificados que ocorrem nas localidades previamente apresentadas foram observados sob três formas: lenhos in situ, presentes em seu depósito original; lenhos exumados, resultantes da denudação da rocha hospedeira; e lenhos ex situ, deslocados por transporte sedimentar ou por ação antrópica, a serem descritos a seguir neste capítulo. Assume-se que os espécimes correspondam às porções do xilema secundário dos troncos (lenhos), em conformidade com Freitas et al. (2008) e Pires e GuerraSommer $(2009,2011)$.

\section{Lenhos in situ}

Correspondem aos lenhos fósseis preservados em seu depósito original, inseridos no interior dos arenitos conglomeráticos da Formação Missão Velha. Os exemplos observados apresentam dimensões variáveis entre 1,5 a $20 \mathrm{~cm}$ de comprimento. Na maioria dos casos, preservam o eixo principal

Tabela 1. Descrição das fácies sedimentares observadas ao longo das Formação Missão Velha, em ordem granodecrescente (Fambrini et al., 2009, 2011, 2017).

\begin{tabular}{|c|c|}
\hline Fácies & Descrição \\
\hline $\mathrm{Ce}$ & Fácies de conglomerados estratificados composta por conglomerados com estratificação plano-paralela. \\
\hline $\mathrm{Ca}$ & Fácies de conglomerados com estratificações cruzadas acanaladas e tabulares. \\
\hline Acg & $\begin{array}{l}\text { Fácies de arenitos conglomeráticos formada de arenitos grossos a conglomeráticos com estratificações cruzadas } \\
\text { acanaladas e plano-paralela e presença de lenhos silicificados. }\end{array}$ \\
\hline Aa & $\begin{array}{l}\text { Fácies de arenitos com estratificação cruzada acanalada composta de arenitos grossos a médios com } \\
\text { estratificações cruzadas acanaladas. }\end{array}$ \\
\hline At & $\begin{array}{l}\text { Fácies de arenitos com estratificação cruzada tabular composta de arenitos médios com seixos esparsos, mal } \\
\text { selecionados, com estratificações cruzadas tabulares. }\end{array}$ \\
\hline Ap & $\begin{array}{l}\text { Fácies de arenitos com estratificação plano-paralela constituída de arenitos médios com seixos esparsos, mal } \\
\text { selecionados, com estratificação plano-paralela. }\end{array}$ \\
\hline Ac & $\begin{array}{l}\text { Fácies de arenitos com laminações cruzadas cavalgantes formada por arenitos finos a muito finos, sílticos, } \\
\text { tabulares, bem estratificados, intercalados com horizontes pelíticos, camadas decimétricas, com estratificação } \\
\text { plano-paralela e com laminações cruzadas cavalgantes. }\end{array}$ \\
\hline $\operatorname{Ar}$ & $\begin{array}{l}\text { Fácies de arenitos finos a médios síticos, com estratificações cruzadas truncantes de baixo-ângulo geradas por } \\
\text { retrabalhamento de sedimentos fluviais. }\end{array}$ \\
\hline Ad & Fácies de arenitos finos com estruturas de deformação (laminações convolutas). \\
\hline SI & $\begin{array}{l}\text { Fácies de siltitos e arenitos finos laminados composta por interestratificações de arenitos finos a muito finos bem } \\
\text { laminados e siltitos. }\end{array}$ \\
\hline $\mathrm{Fl}$ & Fácies de argilitos laminados. \\
\hline Fsm & Fácies de argilitos maciços. \\
\hline$P$ & Fácies de paleossolo. \\
\hline
\end{tabular}


do lenho, paralelos aos estratos, sem padrão de direção azimutal. No afloramento do Alto de Abaiara observaram-se dois fragmentos de lenhos in situ, ambos de dimensões reduzidas $(<2 \mathrm{~cm}$ de comprimento). O primeiro ocorre em um horizonte conglomerático (Fácies $A c g$ ), apresentando arestas arredondadas, subesférico, de coloração ocre, em meio a seixos quartzosos angulosos e subarredondados e de rochas do embasamento, apresentando estriações longitudinais típicas dos fragmentos de lenhos silicificados (Figura 2A). $\mathrm{O}$ segundo ocorre horizontalizado, prolato com relação ao eixo principal, disperso em um nível arenítico médio a grosso (Fácies $A t$ ), ocorrendo de forma proeminente com relação ao afloramento e apresentando estriações características (Figura 2B).

No afloramento das linhas de alta-tensão observaram-se lenhos in situ ocorrendo de duas formas. O primeiro caso ocorre de forma protuberante com relação ao substrato, com aproximadamente $20 \mathrm{~cm}$ de comprimento em seu maior eixo, posicionado horizontalmente entre arenitos médios (Fácies $A t$ ) e um nível centimétrico de aspecto laterítico observado na sucessão da unidade (Figura 3A). O segundo corresponde a uma família de exposições de pequenos fragmentos de lenhos, de dimensões inferiores a $2 \mathrm{~cm}$ de comprimento, ocorrendo em uma lente conglomerática em meio aos arenitos (Fácies $A c g$ ). Destaca-se, nesta exposição, o fraturamento em ângulo reto nas extremidades dos fragmentos de lenhos (Figura 3B).

\section{Lenhos exumados}

Correspondem aos lenhos que ocorrem junto ao substrato parcialmente soterrados pelo regolito. Estão relacionados à exposição de blocos de arenitos conglomeráticos da Formação Missão Velha no entorno dos espécimes, sotopostos ou sobrepostos, sendo os processos erosivos pouco efetivos para transportar os lenhos de maior porte. Os lenhos observados apresentam dimensões variando de 0,3 a $1 \mathrm{~m}$, sendo frequente a exposição de segmentos fraturados em duas, três, ou quatro partes, com planos de quebra preferencialmente diagonais com relação ao eixo de crescimento vertical do lenho. Os lenhos com essa forma de exposição foram observados apenas nas exposições da seção inferior da Serra do Espia (Figuras 4A e 4B). Na seção superior dos afloramentos dessa localidade observou-se um fragmento de lenho de $60 \mathrm{~cm}$ em seu maior eixo por um diâmetro de aproximadamente $50 \mathrm{~cm}$, superficialmente impregnado em

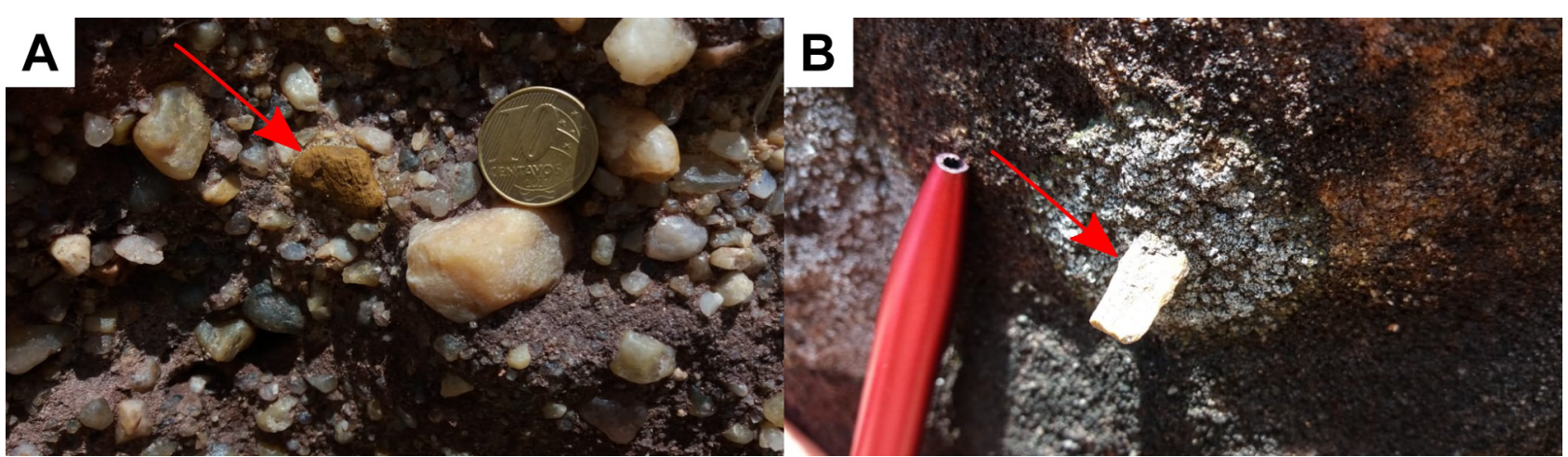

Figura 2. Lenhos silicificados in situ (indicados por setas) na localidade do Alto de Abaiara.

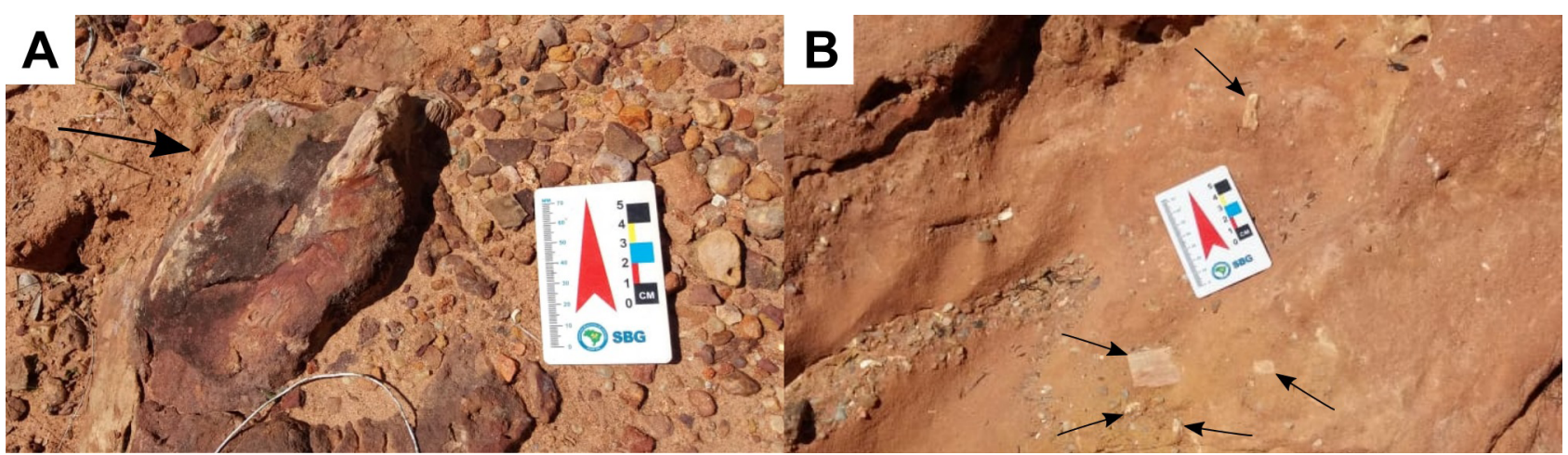

Figura 3. Lenhos silicificados in situ (indicados por setas) nas exposições das linhas de alta-tensão. 


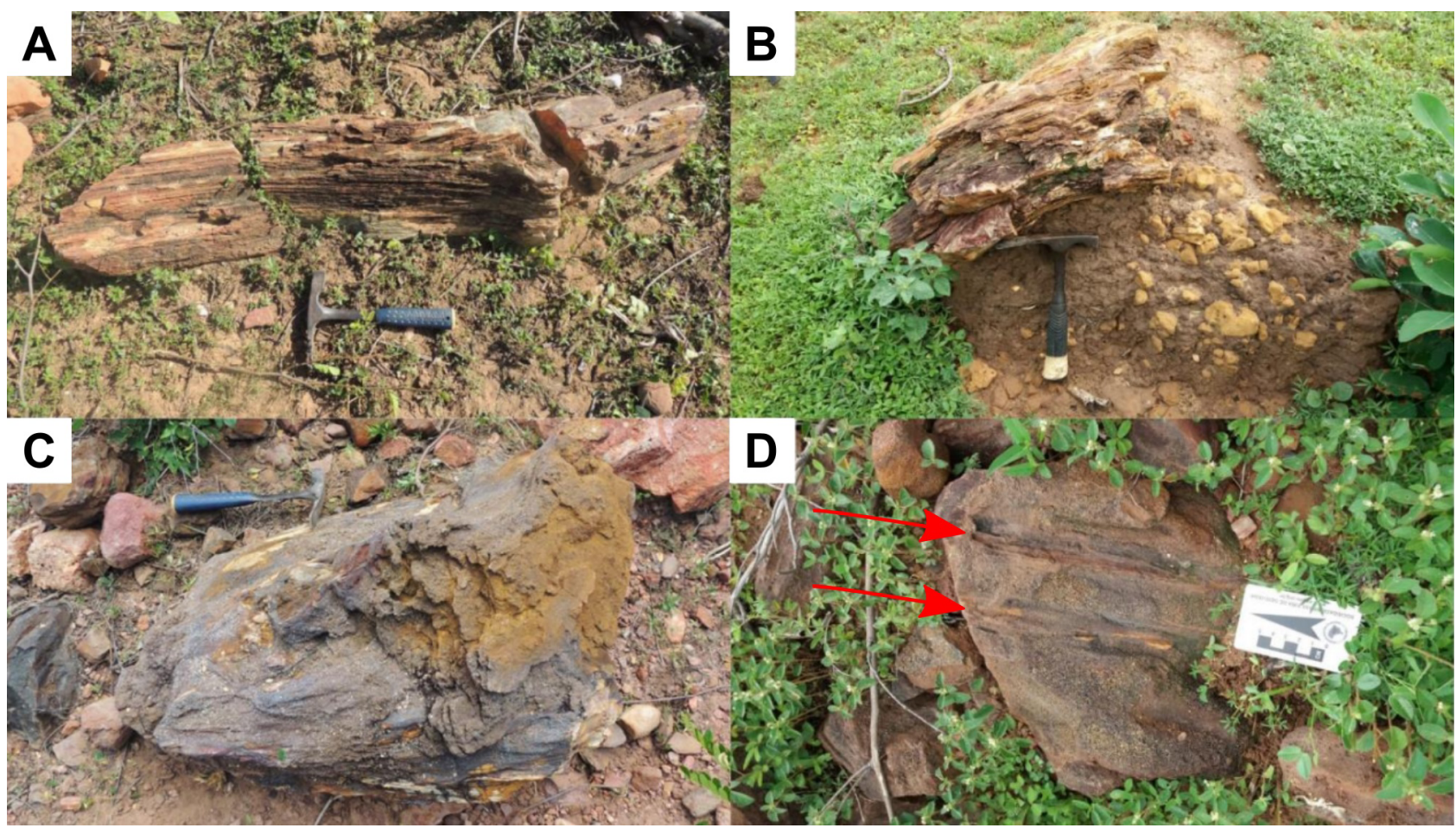

Figura 4. (A) Segmento de lenho silicificado fraturado; (B) fragmento de lenho ocorrendo sobre blocos de arenito; (C) lenho silicificado com fragmento de arenito preservado em sua superfície; (D) moldes de lenho em bloco de arenito (indicados por seta).

ferro e apresentando "encrustado" em sua superfície um fragmento de arenito grosso, com estratificação cruzada preservada (Fácies $A c g$ ) e permineralizado por óxido de ferro (Figura 4C), de sentido relativo de paleocorrente a $60^{\circ}$ com relação ao maior eixo do lenho. Nessa mesma localidade observam-se moldes de lenhos nos blocos de arenitos impregnados em ferro, característicos da porção superior desse afloramento (Figura 4D).

\section{Lenhos ex situ}

Ocorrem nos afloramentos de arenitos conglomeráticos da Formação Missão Velha, totalmente remobilizados sobre o substrato, e suas dimensões podem variar de poucos centímetros a $1 \mathrm{~m}$ de comprimento, havendo sido reportados espécimes com mais de $2 \mathrm{~m}$ de comprimento (e.g. Freitas et al., 2008). Essa forma de exposição caracteriza-se por não apresentar lenhos encalhados no regolito ou moldes de lenhos nos afloramentos, nem relação parental com outros fragmentos, tornando difícil deduzir a distância de transporte desde seu sítio de fossilização. Essa forma de ocorrência é a mais característica para os lenhos encontrados no Geossítio Floresta Petrificada do Cariri (Figura 5A). Ocorrem, e de forma restrita, nas exposições da Cachoeira do Macêdo e da Serra do Espia (Figura 5B).

\section{DISCUSSÃO}

\section{Amplitude estratigráfica}

Os lenhos silicificados observados in situ aparecem nos arenitos grossos a conglomeráticos relacionados à porção superior da Formação Missão Velha, em concordância com descrições de trabalhos anteriores (e.g. Braunn, 1966; Brito, 1987; Ponte e Appi, 1990; Assine, 1992, 2007; Freitas et al., 2008; Fambrini et al., 2009, 2011, 2017). A presença dos lenhos foi um dos critérios diagnósticos empregados por esses autores na definição da unidade, além de critérios sedimentológicos, estratigráficos, paleontológicos, mineralógicos e estruturais. Estudos estratigráficos e faciológicos compreendendo as formações Brejo Santo (Fambrini et al., 2012a) e Abaiara (Fambrini et al., 2012b), respectivamente sotoposta e sobreposta à Formação Missão Velha, não constatam a presença dos lenhos silicificados, tornando confiável a afirmação de que podem ser exclusivos da Formação Missão Velha, restritos à Missão Velha Superior (sensu Fambrini et al., 2011, 2017).

\section{Caráter tafonômico}

A definição de caráter tafonômico de Behrensmeyer e Hook (1992) divide as assembleias fitofossilíferas em três grupos, 


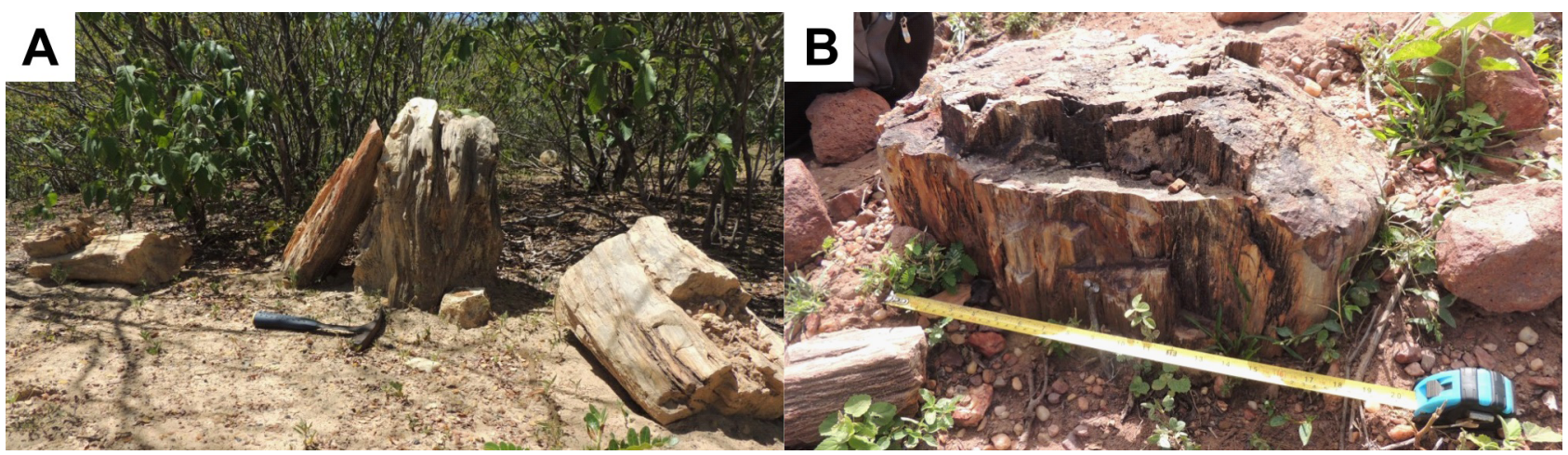

Figura 5. (A) Fragmentos de lenhos ex situ deslocados por ação antrópica no Geossítio Floresta Petrificada; (B) Fragmento de lenho transportado na Serra do Espia (escala: $30 \mathrm{~cm}$ ).

descritos por Martín-Closas e Gomez (2004) de acordo com suas características bioestratinômicas:

- tafofloras autóctones: conjuntos de vegetais fósseis preservados em seu local de crescimento e morte;

- tafofloras hipoautóctones/parautóctones: conjuntos florísticos transportados a uma pequena distância de seu local de crescimento, porém dentro dos arredores de seu habitat original;

- tafofloras alóctones: assembleias de fitofósseis deslocados do seu habitat original e dos seus arredores.

Os lenhos silicificados observados em seu depósito original na Formação Missão Velha são fragmentos de dimensões variadas dispersos na matriz arenítica e conglomerática, não sendo observados em posição vertical, nem conectados a raízes ou incluídos no paleossolo presente na unidade, ainda que estejam sotopostos aos níveis estratigráficos portadores dos lenhos. Trata-se de porções do xilema secundário de caules de coníferas (Freitas et al., 2008; Pires e GuerraSommer, 2009, 2011), que apresentam fragmentação e seleção de órgãos. Isso torna pouco provável que se trate de uma tafoflora autóctone ou hipoautóctone. É mais plausível que esses espécimes tenham sofrido transporte significativo do seu local de vida, sendo injetados no interior dos canais fluviais, tratando-se, sob o ponto de vista tafonômico, de uma assembleia alóctone, embora características intrínsecas aos aspectos sedimentológicos dos lenhos in situ, a serem discutidas adiante, possibilitem questionamentos com relação ao processo de silicificação dos lenhos.

Os fragmentos de lenhos exumados que ocorrem na Serra do Espia jazem em uma região desmatada, denunciando denudação intensa, que pode ser constatada pela coexistência de lenhos silicificados e blocos de arenito parcialmente soterrados por um neossolo regolítico. É provável que a direção preferencial W-E dos lenhos de maior dimensão esteja relacionada com a denudação da Serra do Espia, e não com a sua disposição original in situ propriamente dita, ainda que o transporte desse material não deva ser superior a poucos metros, para a seção inferior, e seja centimétrico, para a seção superior, evidenciado pela presença de um lenho com um fragmento de arenito incrustante no seu topo, portanto, sem ter sofrido sequer rolamento em torno de seu próprio eixo (Figura 4C).

Adicionalmente, deve-se mencionar que a angulação entre o eixo principal do lenho e o sentido da paleocorrente do fragmento incrustante apresenta ângulos de $60^{\circ}$ positivos, evidenciando uma posição diagonal do lenho em relação ao sentido do fluxo. A uniformidade de direções estáveis de transporte de lenhos em leitos fluviais está relacionada à largura e à profundidade dos canais fluviais, ou a eventos catastróficos sobre áreas florestadas (Wnuk e Pfefferkorn, 1987; Gurnell et al., 2002; Abbe e Montgomery, 2003). A pequena amostragem de lenhos de grande porte in situ ou pouco transportados inviabiliza quaisquer proposições a respeito da direção preferencial dos lenhos em relação ao sentido da paleocorrente. Entretanto, considerando-se que a orientação de lenhos se torna, gradativamente, paralela à corrente à medida que o canal se aprofunda (Gurnell et al., 2002), é possível supor que os canais fluviais da Formação Missão Velha seriam amplos e rasos. McKnight et al. (1990) e Keller e Hendrix (1997) descrevem lenhos silicificados de coníferas paralelizados ao sentido da corrente em depósitos do Jurássico Superior na Ásia Central. Esse comportamento regional é esperado para depósitos fluviais de alta energia em climas de monções, com grandes tempestades provocando morte e sepultamento dos vegetais (Capretz, 2010).

A abundância de largos lenhos fósseis na Formação Missão Velha, significando a presença de florestas nas áreas fontes, levou à interpretação clássica da predominância de climas mais úmidos no ambiente deposicional da unidade (e.g. Braunn, 1966; Fambrini et al., 2011). Fambrini et al. (2011) destacaram a ausência aparente de lenhos silicificados, assim como o caráter efêmero dos sistemas fluviais na seção inferior da unidade e a abundância de lenhos juntamente a um caráter perene do sistema fluvial (presença de macroformas) 
na seção superior da unidade, levando os autores a sugerir que entre as sequências há considerável aumento nas condições de umidade. Essa interpretação é coerente, considerando-se que a unidade não apresenta indicadores climáticos mais óbvios de origem química ou bioquímica.

Paralelamente, Pires e Guerra-Sommer (2011), por meio do estudo de anéis de crescimento nos lenhos silicificados, apresentariam conclusões mais detalhadas acerca desses padrões paleoclimáticos. As autoras sugerem um ambiente de crescimento irregular com eventos climáticos extremos, porém com boas condições para o desenvolvimento das árvores, com grande variabilidade anual de suprimento de água, assemelhando-se ao clima de monções, segundo a classificação de Köppen (1936), em que a sazonalidade da circulação de monções resulta em invernos frios e secos e verões quentes e úmidos nas regiões continentais.

Costa et al. (2014), em estudo de condições diagenéticas, observaram que nos depósitos da Formação Missão Velha destaca-se a infiltração mecânica de argilas, que sugerem enxurradas episódicas e em profundidades rasas sob climas semiáridos. Contudo, esse fenômeno não se distingue em comportamento nas seções inferior e superior da unidade.

\section{Sedimentologia}

As feições observadas no lenho de pequeno porte das linhas de alta-tensão (Figura 3B) são semelhantes às observadas nos lenhos in situ presentes no Morro do Cruzeiro (Figura 6), tratando-se de planos de fratura ortogonais à estriação longitudinal do lenho. A presença desses planos evidencia que ocorreram, simultaneamente, fragmentação e retrabalhamento de lenhos silicificados que se comportam como clastos na matriz arenosa. No segundo caso, os lenhos provêm do retrabalhamento de sua fonte original de fossilização. Já as feições sedimentológicas de arredondamento e esfericidade observadas nos lenhos in situ de pequeno porte no afloramento do Alto de Abaiara levam à interpretação de que os lenhos também sejam provenientes de retrabalhamento das camadas fossilíferas, e, por serem fragmentos menores, foram transportados a maiores distâncias.

\section{Significado geológico}

As ocorrências fitofossilíferas dos lenhos silicificados na Formação Missão Velha revelam estágios sequenciais de exposição. Inicialmente, os lenhos ocorrem in situ em seu sítio de sedimentação e fóssil diagênese, registrados no afloramento das linhas de alta-tensão (Figura 3A) e, possivelmente, no interior dos depósitos entre Serra do Espia e Geossítio Floresta Petrificada; alguns espécimes de lignifósseis, devido ao seu grande porte, sofreram pequeno transporte e faturamento, sendo expostos por meio de processos iniciais de denudação, permanecendo quase intactos, aflorando à superfície por serem mais resistentes à erosão do que as rochas portadoras (Figuras 2B e 4A), como é constatado na Serra do Espia; com a continuidade dos processos erosivos, os lenhos são reduzidos a fragmentos cada vez menores e passam a comportar-se como matacões e blocos (Figuras 4C e 5), como os que jazem no Geossítio Floresta Petrificada; e com a continuidade da degradação física, são cominuídos à fração seixo e dispersam-se em forma de cascalheiras, como é observado na Cachoeira do Macêdo. Nesse caso, tornam-se de difícil identificação ou indetectáveis a olho nu, à medida que as estriações originais dos lenhos são degradadas, frequentemente se confundindo com cascalhos de rochas metamórficas ou quartzo de veios, tornando necessária uma investigação petrográfica sistemática desse material para identificação.

\section{CONSIDERAÇÕES FINAIS}

Observando-se os tipos de ocorrência dos lenhos silicificados da Formação Missão Velha do ponto de vista tafonômico e sedimentológico, foi possível chegar às seguintes conclusões:

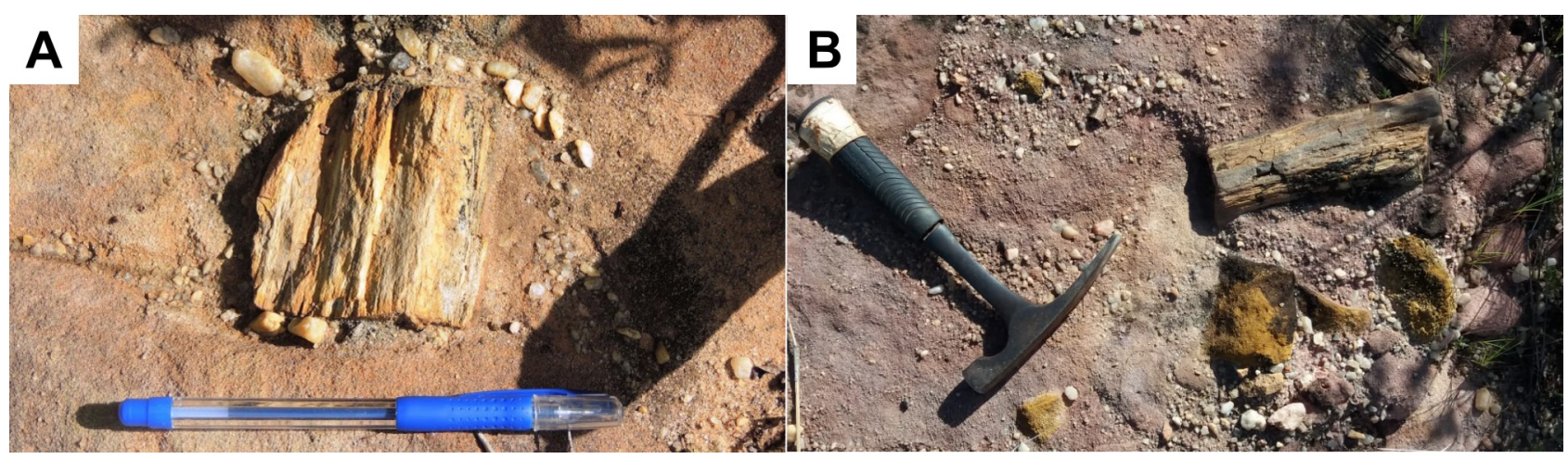

Figura 6. Lenhos silicificados in situ no Morro do Cruzeiro, Abaiara-CE, apresentando planos de fratura ortogonais ao maior eixo dos troncos. 
- Os tipos de exposição observados podem ser categorizados nos seguintes estágios sequenciais de ocorrências: lenhos in situ; lenhos exumados; e lenho ex situ;

- Os lenhos in situ, ou seja, que ainda não foram removidos de sua rocha hospedeira, são encontrados como fragmentos de dimensões variadas dispersos na matriz arenítica e conglomerática da porção superior da Formação Missão Velha, não havendo sido observados verticalizados, nem relacionados a raízes ou ao paleossolo presente na unidade, tratando-se de uma assembleia alóctone;

- É possível que os lenhos ocorrentes na Serra do Espia tenham sofrido transporte apenas de ordem centimétrica, sugerindo que nessa localidade haja ainda grande quantidade de lenhos in situ de grande porte no interior de seus depósitos, hipótese reforçada pela presença de moldes de lenhos no arenito e pela exposição de porção basal de lenho silicificado;

- Tanto os lenhos in situ como ex situ apresentam fragmentação e seleção de órgãos (xilema secundário de lenho), sugerindo submissão a transporte significativo desde seu local de vida, com sua injeção no interior dos canais fluviais;

- Analisando-se as direções de paleocorrente da unidade e aquelas do eixo do lenho em uma única exposição, nota-se diferença de $60^{\circ}$ positivos, evidenciando-se que esse espécime não teve acomodação para transporte na lâmina d'água, possivelmente devido à pouca profundidade dos canais, apesar da alta energia de descarga, reforçando o caráter efêmero do sistema fluvial;

- Fragmentos de lenhos in situ comportando-se como seixos, considerados neste trabalho como "secundários", foram observados no Alto de Abaiara e nas linhas de alta-tensão. Considera-se a possibilidade de serem resultantes do retrabalhamento sedimentar das camadas fossilíferas. É possível que esse mecanismo de sedimentação esteja relacionado à atividade tectônica dos estágios iniciais de rifte, embora essa questão careça de mais estudos;

- As cascalheiras que ocorrem nos afloramentos da Formação Missão Velha apresentam muitos fragmentos degradados de lenhos silicificados que, frequentemente, se confundem com cascalhos de rochas metamórficas ou quartzo de veios. Os autores sugerem que deva ser feita uma investigação petrográfica sistemática para identificação desse material.

\section{AGRADECIMENTOS}

Este trabalho é parte da dissertação de mestrado de Aerson Moreira Barreto Junior, que agradece a correta orientação e o companheirismo, a amizade, a paciência e a atenção do Prof. Dr. Gelson Luis Fambrini ao longo do mestrado.
Os autores agradecem ao Laboratório de Geologia Sedimentar e Ambiental (UFPE), pela viabilização do espaço físico, e à Coordenação de Aperfeiçoamento de Pessoal de Nível Superior (CAPES), pelo fornecimento da bolsa de mestrado de Aerson Moreira Barreto Junior. Os autores também agradecem aos revisores e aos editores da revista, pela exímia leitura do texto com várias sugestões de aprimoramento ao manuscrito original.

\section{REFERÊNCIAS}

Abbe, T. B., Montgomery, D. R. (2003). Patterns and processes of wood debris accumulation in the Queets rivers basin, Washington. Geomorphology, 51(1-3), 81-107. https://doi. org/10.1016/S0169-555X(02)00326-4

Alemão, F. F., Alemão, M. F. (1862). Trabalhos da Commissão scientifica de exploração. Rio de Janeiro: Typographia Universal de Laemmert.

Assine, M. L. (1992). Análise estratigráfica da Bacia do Araripe, Nordeste do Brasil. Revista Brasileira de Geociências, 22(3), 289-300.

Assine, M. L. (2007). Bacia do Araripe. Boletim de Geociências da Petrobras, 15(2), 371-389.

Behrensmeyer, A. K., Hook, R. W. (1992). Paleoenvironmental contexts and taphonomic modes in the terrestrial fossil record. In: A. K. Behrensmeyer, A. K. Damuth, W. A. Dimichele, R. Potts (Eds.), Terrestrial ecosystems through time: evolutionary paleoecology of terrestrial pants and animals, 1, 15-138. Chicago: University of Chicago Press.

Beurlen, K. (1963). Geologia e estratigrafia da Chapada do Araripe. XVII Congresso Brasileiro de Geologia, suplemento, 1-47. Recife: SBG-SUDENE.

Branner, J. C. (1890). The Cretaceous and Tertiary Geology of the Sergipe-Alagoas Basin of Brazil. Transactions of the American Philosophical Society, 16(3), 369-434. https://doi. org/10.2307/1005398

Braunn, O. P. G. (1966). Estratigrafia dos sedimentos da parte inferior da Região Nordeste do Brasil (Bacias do Tucano-Jatobá, Mirandiba e Araripe). Boletim 236, 75 p. Rio de Janeiro: DNPM/DGM.

Brito, L. M. (1987). As unidades litoestratigráficas da passagem Jurássico-Cretáceo do Nordeste do Brasil. Revista Brasileira de Geociências, 17(2), 81-85. 
Capretz, R. L. (2010). Paleoecologia e tafonomia da Floresta Petrificada do Tocantins Setentrional (Bacia do Parnaiba, Permiano). Tese (Doutorado). Rio Claro: Instituto de Geociências e Ciências Exatas - UNESP. Disponível em: http:/hdl.handle.net/11449/103007. Acesso em: 6 out. 2021.

Cavalcanti, V. M. M., Viana, M. S. S. (1992). Revisão estratigráfica da Formação Missão Velha, Bacia do Araripe, Nordeste do Brasil. Anais da Academia Brasileira de Ciências, 64(2), 155-168.

Costa, A. B. S., Córdoba, V. C., Jardim de Sá, E. F., Scherer, C. M. S. 2014. Diagênese dos arenitos da Tectonossequência Rifte na Bacia do Araripe, NE do Brasil. Brazilian Journal of Geology, 44(3), 457-470. https://doi.org/10.5327/ Z2317-4889201400030008

Fambrini, G. L., Buarque, B. V., Menezes Filho, J. A. B., Valença, L. M. M., Araújo, J. T., Neumann, V. H. M. L. (2012a). Análise estratigráfica da Formação Abaiara (Neocomiano), Bacia do Araripe, NE do Brasil: implicações para a implantação da fase rifte das bacias fanerozóicas brasileiras. XLVI Congresso Brasileiro de Geologia. Santos: SBG. CD-ROM.

Fambrini, G. L., Lemos, D. R., Tesser Junior, S., Araújo, J. T., Silva Filho, W. F., Souza, B. Y. C., Neumann, V. H. M. L. (2011). Estratigrafia, arquitetura deposicional e faciologia da Formação Missão Velha (Neojurássico-Eocretáceo) na área-tipo, Bacia do Araripe, Nordeste do Brasil: exemplo de sedimentação de estágio de início de rifte a clímax de rifte. Geologia USP. Série Cientifica, 11(2), 55-87. http:// dx.doi.org/10.5327/Z1519-874X2011000200004

Fambrini, G. L., Neumann, V. H. M. L., Barros, C. L., Agostinho, S. M., Galm, P. C., Araújo, J. T., Menezes Filho, J. A. B. (2012b). Análise de fácies da Formação Brejo Santo, Bacia do Araripe, Nordeste do Brasil: implicações paleodeposicionais. Estudos Geológicos, 22(1), 131-155.

Fambrini, G. L., Neumann, V. H. M. L., Menezes Filho, J. A. B., Silva Filho, W. F., Oliveira, E. V. (2017). Facies architecture of fluvial Missão Velha Formation (Neojurassic-Eocretaceous), Araripe Basin, Northeast Brazil: paleogeographic and tectonic implications. Acta Geologica Polonica, 67(4), 515-545. https://doi.org/10.1515/agp-2017-0029

Fambrini, G. L., Tesser Junior, S., Neumann, V. H. M. L., Souza, B. Y. C., Silva Filho, W. F. (2009). Fácies e sistemas deposicionais na área-tipo da Formação Missão Velha, Bacia do Araripe, Nordeste do Brasil. Estudos Geológicos, 19(1), 161-190.
Freitas, F. I., Hessel, M. H., Nogueira Neto, J. A. (2008). Troncos fósseis da Formação Missão Velha na porção leste da Bacia do Araripe, Ceará. Revista de Geologia, 21(2), 193-206.

Ghignone, J. I. (1979). Geologia dos sedimentos fanerozóicos do Estado da Bahia. In: H. A. Inda (Ed.). Geologia e Recursos Minerais do Estado da Bahia, 1, 24-117. Salvador: Secretaria do Estado e Energia da Bahia.

Gurnell, A. M., Piégay, H., Swanson, F. J., Gregory, S. V. (2002). Large wood and fluvial processes. Freshwater Biology, 47(4), 601-619. https://doi.org/10.1046/j.1365-2427.2002.00916.x

Hartt, C. F., Agassiz, L. (1870). Geology and physical geography of Brazil. Boston: Osgood \& Co.

Keller, A., Hendrix, M. (1997). Palaeoclimatologic analysis of a Late Jurassic Petrified Forest, Southeastern Mongolia. Palaios, 12(3), 282-291. https://doi.org/10.2307/3515428

Köppen, W. (1936). Das geographische System der Klimate. In: W. Köppen, R. Geiger (Eds). Handbuch der Klimatologie, 1, 1-44. Berlim: Gebrüder Bornträger.

Kuchle, J., Scherer, C. M. S., Born, C. C., Alvarenga, R. S., Adegas, F. A. (2011). A contribution to regional stratigraphic correlations of the Afro-Brazilian depression - The Dom João Stage (Brotas Group and equivalent units - Late Jurassic) in Northeastern Brazilian sedimentary basins. Journal of South American Earth Sciences, 31(4), 358-371. https:// doi.org/10.1016/j.jsames.2011.02.007

Martín-Closas, C., Gomez, B. (2004). Taphonomie des plantes et interprétations paléoécologiques: une syntèse. Geobios, 37(1), 65-88. https://doi.org/10.1016/j.geobios.2003.01.006

McKnight, C. L., Graham, S. A., Carroll, A. R., Gan, Q., Dilcher, D. L., Zhao, M., Liang, Y. H. (1990). Fluvial sedimentology of an Upper Jurassic Petrified Forest assemblage, Shishu Formation, Jungarr Basin, Xinjiang, China. Palaeogeography, Palaeoclimatology, Palaeoecology, 79(1-2), 1-9. https://doi.org/10.1016/0031-0182(90)90102-D

Neumann, V. H. M. L., Cabrera, L. (1999). Una nueva propuesta estratigrafica para la tectonosecuencia post-rift de la Cuenca de Araripe, Noreste de Brasil. V Simpósio sobre o Cretáceo do Brasil, 279-285. Serra Negra: UNESP.

Pires, E. F., Guerra-Sommer, M. (2009). Plant-arthropod interaction in the Early Cretaceous (Berriasian) of the Araripe Basin, Brazil. Journal of South American Earth Sciences, 27(1), 50-59. https://doi.org/10.1016/j.jsames.2008.09.004 
Pires, E. F., Guerra-Sommer, M. (2011). Growth ring analysis of fossil coniferous woods from early cretaceous of Araripe Basin (Brazil). Anais da Academia Brasileira de Ciências, 83(2), 409-423. http://dx.doi.org/10.1590/S0001-37652011005000005

Ponte, F. C., Appi, C. J. (1990). Proposta de revisão da coluna litoestratigráfica da Bacia do Araripe. XXXVI Congresso Brasileiro de Geologia, 211-226. Natal: SBP.

Silva, D. R., Mizusaki, A. M. P., Milani, E. J., Pimentel, M. (2012). Depositional ages of Paleozoic and Mesozoic prerift supersequences of the Recôncavo Basin in northeastern Brazil: A $\mathrm{Rb} / \mathrm{Sr}$ radiometric study of sedimentary rocks. Journal of South American Earth Sciences, 37, 13-24. http:// dx.doi.org/10.1016/j.jsames.2011.12.006

Silva Filho, W. F., Ferreira, L. A. N., Barreto Junior, A. M., Nogueira Neto, J. A. (2015). Representações da pedra-pau e do Geopark Araripe na área do Geossítio Floresta Petrificada do Cariri no Geopark Araripe, Milagres - Ceará. III Simpósio Brasileiro de Patrimônio Geológico, 336-339. Lençóis: UEFS.
Silveira, A. C., Silva, A. C., Cabral, N. R. A. J., Schiavetti, A. (2012). Análise de efetividade de manejo do Geopark Araripe-Estado do Ceará. Geociências, 31(1), 117-128.

Sousa-Brasil, T. P. (1863). Ensaio estatístico da província do Ceará. São Luís: Typographia de B. de Mattos.

Viana, C. F. (1980). Cronoestratigrafia dos sedimentos da margem continental brasileira. XXXI Congresso Brasileiro de Geologia, 832-843. Balneário Camboriú: SBG.

Viana, C. F., Gama Junior, E. G., Simões, I. A., Mourea, J.A., Fonseca, J. R., Alves, R. J. (1971). Revisão estratigráfica da Bacia do Recôncavo-Tucano. Boletim Técnico da Petrobras, 14(3-4), 157-192.

Wnuk, C., Pfefferkorn, H. W. (1987). A Pennsylvanian-age terrestrial storm deposit: using plant fossils to characterize the history and process of sediment accumulation. Journal of Sedimentary Petrology, 57(2), 212-221. https://doi. org/10.1306/212F8AE9-2B24-11D7-8648000102C1865D 